\title{
Prescribing Pattern and Prescription Errors: A Study at a Tertiary Care Hospital of Bangladesh
}

\author{
Farzana Sultana', Ajijur Rahman', Tripti Rani Paul², Md. Shahid Sarwar, \\ Md. Anwar Ul Islam ${ }^{1}$ and Mamunur Rashid ${ }^{3}$ \\ ${ }^{1}$ Department of Pharmacy, Rajshahi University, Rajshahi-6205, Bangladesh \\ ${ }^{2}$ Department of Pharmacy, Khwaja Yunus Ali University, Sirajganj-6751, Bangladesh \\ ${ }^{3}$ Department of Pharmacy, Southeast University, Dhaka-1213, Bangladesh
}

Received: September 01, 2014; Accepted: December 04, 2014

\begin{abstract}
Irrational prescribing of drugs is a major health concern in developing countries like Bangladesh. A study was therefore undertaken in a hospital, situated in Rajshahi region of Bangladesh, to find the prescribing pattern and to detect the prescription errors to the admitted patients. Prescriptions of 200 patients were collected from various departments of the hospital over a period of three months. Prescription pattern was analyzed using general indicators suggested by WHO and prescribing errors were determined by comparing the prescribed drugs with national standard treatment guidelines, textbooks and authentic online resources. The average number of drugs per prescription was found to be 4.89 and $76.5 \%$ prescriptions contained complex regimen. In this study, we found no prescription with generic name. The percentage of prescription with antibiotics was $78 \%$ that was $15.95 \%$ of total drugs. The injectable preparations used were $17.18 \%$ of total 978 drugs. About 769 (3.85 per prescription) prescription errors were identified from 978 prescribed drugs. The name of 35 prescribed drugs was not clear due to illegible hand writing. The dose strength was missing for 279 drugs and 31 drugs had improper abbreviation. The study also identified 409 drug interactions. About 6.5\% prescription orders were identified for the patients with kidney and urinary problems and there was no dose adjustment. Frequency of occurrence of prescription errors found during the study can be rated high. The prescription pattern and the prescription errors have indicated the need to establish proper system of recording and analyzing therapy before writing a prescription in order to promote rational drug therapy.
\end{abstract}

Key words: Rational drug therapy, Prescribing pattern, Prescription error, Polypharmacy, Generic name.

\section{Introduction}

Drug utilization study as defined by the WHO, is a structured process which is used to assess the quality of drug therapy by engaging in the evaluation of data on drug prescribing, dispensing and patient use in a given health care environment, against predetermined, agreed upon criteria and standards, with special emphasis on the resulting medical, social, and economic consequences (Jimoh et al., 2011). Drug utilization studies seek to monitor, evaluate and suggest modifications in the prescribing practices with the aim of making the medical care rational and cost effective (Jimoh et al., 2011). A study of prescription pattern is an important tool to determine rational drug therapy, maximize utilization of resources and to reduce prescription errors. In 2008, the world health organization (WHO) reported that more than half of all medicines are prescribed dispensed or sold (Silva, 2009) inappropriately and that half of all patients fail to take them correctly.

Prescription errors are an unfortunate reality at hospitals. Approximately, $30 \%$ of problems occurring during hospitalization are related to medication errors (Silva, 2009). Errors are possible at any step of the care process, from medication selection to drug administration. Numerous studies have shown that patients admitted to hospitals are harmed as a result of medication errors, majority of which are due to the errors in prescriptions (Leape et al., 1995; Barber et al., 1998; Pote et al., 2007).

A clinically meaningful prescription error occurs when, as a result of a prescribing decision or prescription

Correspondence to: Mamunur Rashid; E-mail: mamun69jp@yahoo.com 
writing process, there is an unintentional significant reduction in the probability of treatment being timely and effective or increase in the risk of harm when compared with generally accepted practice (Dean et al., 2000). The medication errors are more common because of polypharmacy. The majority of errors are not only due to reckless behavior on the part of health care providers, but also occurs as a result of the speed and complexity of the medication use cycle, combined with faulty systems, processes and conditions that lead people to make mistakes or fail to prevent them (Barker et al., 2002; Moyen et al., 2008). Bates et al. (1995) reported that 56\% of adverse drug events occurred during the prescribing stage and 34\% during the administration stage; only $4 \%$ occurred at the dispensing stage.

National Drug policy (NDP, 2005) states that only registered drugs should be allowed to distribute and sell throughout the country under person having professional qualification and holding professional license. NDP (2005) again indicates that no drugs other than OTC should be sold or dispensed without prescriptions. Rational use of drugs (RUD) should be ensured by conducting survey on the system of prescribing, dispensing and patient compliance. Monitoring and reporting adverse drug reactions should be done seriously to ensure safe and rational use of drugs in the country.

To improve the overall drug use, especially in developing countries, international agencies like the world health organization (WHO) and the international network for the rational use of drugs (INRUD) have engaged themselves to evolve standard drug use indicators (Biswas et al., 2001). These indicators help us to improve our performance during different time periods (Yeasmeen $e t$ $a l ., 2011)$. The rational prescribing skills of clinicians can be assessed by conducting periodic prescription audits. In a teaching hospital as the medical teachers are the role models for the students, the prescribing behavior of the teachers can affect the students. These audits and studies can also influence the policy makers by informing them about the quality of drug use in the health facility (Desai, 2001; Bimo et al., 1999).

There is an urgent need to ensure that patients are always given evidence-based, cost-effective and rational treatments. Gaining insight into physician's pattern in order to identify prescribing problem is the fundamental step in improving the quality of prescription and patient care. Therefore, the present study was planned to understand the prescription pattern of inpatients in a government hospital of Bangladesh and to detect the incidence of prescribing errors for admitted patients.

\section{Methods}

Study area and data collection process: A crosssectional study was conducted to the inpatients in a 1000 bed teaching hospital, Rajshahi, Bangladesh. This is a Government hospital and serves as a central provider for advanced health care in the northern part of Bangladesh. Prescriptions were randomly collected from inpatients department of the participating units during winter season (October to December 2011). A total of 200 patients were selected after 24 hours of admission and the patients who were under the supervision of responsible physician. All the data for the analysis extracted from the patient's case note, treatment chart and by interviewing patients into a data collection form.

Study parameters: General prescription pattern: Each individual indicator was analyzed by using the following drug indicators suggested by the WHO (Biswas et al., 2001) to evaluate the drug prescription pattern:

a. Total number of drugs in the prescription

b. Average number of drugs per prescription.

c. Percentage of drugs prescribed by generic name.

d. Percentage of prescriptions with antimicrobials prescribed.

e. Percentage of prescriptions with inject able preparations

f. Whether the dosage of the drugs prescribed is appropriate.

Categories of prescription errors: A clinically meaningful prescribing error occurs as a result of a prescribing decision or prescription writing process as mentioned below:

Errors in prescribing writing process

- Absence of drug information

- Use of inaccurate abbreviation

- Illegible hand writing

- Errors in decision process/decision errors

- Drug interaction

- Therapeutic duplication 
Data analysis process: The data includes demographic variables, date, name of medication, dosage forms, doses and frequency. Data were edited, coded and entered into SPSS (Statistical package for social service) version 15. All drugs were classified according to the Anatomical Therapeutic Classification System (ATC) recommended by the World Health Organization (WHO). The drug-drug interactions were checked using Medscape drug interaction checker. Prescribing errors were assesses by comparing the prescribed drugs with national standard treatment guidelines, textbooks and software. Descriptive statistics like frequency and other parameters were computed to determine the overall prevalence of prescribing errors. The whole procedure was completed with consent of authorities of the concerned institutions and confidentiality of the prescriptions was maintained strictly.

\section{Results and Discussion}

A total of 200 patient's prescription files were studied. The majority of the patients were male 112 (56\%) and 88 (44\%) patients were female with $73.5 \%$ of them aged between 18-60 years. Among these patients, $17.5 \%$ and $37.5 \%$ were illiterate and from primary education level, respectively and 70 (35\%) had previous records of hospitalization (Table 1). According to the study, the frequency of prescribing errors was 769 (3.85 per patient) (Figure 1).

Table 1. Characteristics of patients admitted to the hospital.

\begin{tabular}{lll}
\hline Variables & Characteristics & Frequency \\
\hline Age & $\leq 17$ years & $19(9.5 \%)$ \\
& 18- 60 years & $147(73.5 \%)$ \\
& $>60$ years & $34(17 \%)$ \\
Gender & Male & $112(56 \%)$ \\
& Female & $88(44 \%)$ \\
Educational level & Uneducated & $35(17.5 \%)$ \\
& Primary & $75(37.5 \%)$ \\
& Secondary & $65(32.5 \%)$ \\
Length of stay & 1-5 days & $100(50 \%)$ \\
& 6-15 days & $77(38.5 \%)$ \\
& $>15$ days & $23(11.5 \%)$ \\
Regimen taken & Complex & $153(76.5 \%)$ \\
& Not complex & $47(23.5 \%)$ \\
\hline
\end{tabular}

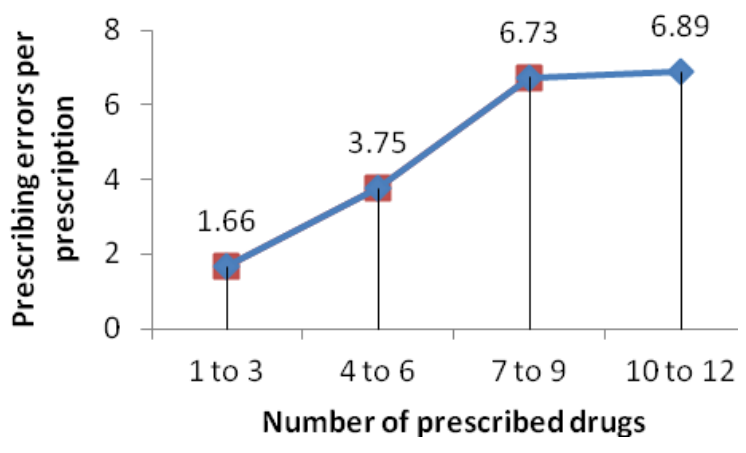

Figure 1. Frequency of errors in the prescriptions.

\section{Prescription pattern}

In the study, a total of 978 drugs were prescribed to 200 patients with an average of 4.89 drugs per prescription. It was more than that reported in most of the studies conducted in government setups across Indian cities, the closest being Delhi 3.03 (Biswas et al., 2001). International studies report values ranging from 1.3 in Zimbabwe (Hogerzeil et al., 1993) to 4.51 in Pakistan (Das et al., 2001). A staggering $76.5 \%$ of prescriptions had 4 or more drugs revealed a trend of polypharmacy.

The use of generic preparations was found to be much in vogue. No drugs were prescribed by their generic names in this study. It is important to note that drugs should be prescribed in their generic names to avoid confusion. Although there are both advantages and disadvantages of generic prescribing, there is more to gain than to lose by this practice, especially in a teaching hospital which has a dual responsibility of providing patient service as well as medical education.

The percentage of prescriptions with antibiotics was $78 \%$. According to WHO $15-25 \%$ of prescriptions with antibiotics are expected in most of the developing countries, where infectious diseases are more prevalent (Lamichhane et al., 2006). This figure is very high in comparison to some of the developing countries. Various studies from India also report a high rate ranging from 4080\% (Kumari et al., 2008).

Drugs for acid-related disorders $(204,20.86 \%)$ were the most frequently prescribed drugs followed by antibacterial agents for systemic use, analgesics, antiinflammatory and anti-rheumatic products and vitamins and minerals were 156 (15.95\%), 73 (7.46\%), 54 (5.52\%) and $47(4.8 \%)$, respectively. Table 2 shows drug use 
indicators found from our study. More than half of the drugs $591(60.43 \%)$ belonged to tablet dosage form and $168(17.18 \%)$ drugs were injectable preparations (Table 2).

Table 2. Pattern of WHO core drug use indicators.

\begin{tabular}{ll}
\hline Characteristics & Value \\
\hline Total number of prescriptions & 200 \\
Total number of drugs prescribed & 978 \\
$\begin{array}{l}\text { Average number of drugs per prescription } \\
\% \text { of drugs prescribed by generic name }\end{array}$ & 4.89 \\
$\%$ of prescriptions containing antimicrobial & $156(15.95 \%)$ \\
$\begin{array}{l}\text { agents } \\
\% \text { of prescriptions with drugs for acid related } \\
\text { disorders }\end{array}$ & $204(20.86 \%)$ \\
$\begin{array}{l}\% \text { of prescriptions with inject able } \\
\text { preparations }\end{array}$ & $168(17.18 \%)$ \\
$\begin{array}{l}\text { Percentage of prescriptions with tablet } \\
\text { dosage form }\end{array}$ & $591(60.43 \%)$ \\
\hline
\end{tabular}

\section{Prescription errors}

A wide range of different types of errors associated with handwritten prescription orders in the teaching hospital were found in the present study. These orders were intended by the physicians for admitted patients having one medical problem or more. From a total of 200 medication orders, 769 prescribing errors were detected representing 3.85 errors per prescription. In this study, errors in the prescription writing process were found to be 345 representing $44.86 \%$ of total errors and decision errors were found to be 424 representing $55.14 \%$ of the total errors (Table 3 ).

Table 3. Different types of prescribing errors.

\begin{tabular}{ll}
\hline \multicolumn{2}{c}{ Errors in prescription writing process $(\mathbf{n}=\mathbf{3 4 5})$} \\
\hline Type of errors & Frequency $(\%)$ \\
Absence of strength of medicine(s) & $279(36.28 \%)$ \\
Illegible hand written medicine(s) & $35(4.55 \%)$ \\
Improper abbreviation & $31(4.03 \%)$ \\
\hline Errors in prescription for decision $(\mathbf{n = 4 2 4})$ \\
\hline Drug interactions & $409(53.19 \%)$ \\
Therapeutic duplication & $15(1.95 \%)$
\end{tabular}

Table 4. Strength of medicines was not stated where a medicine is present in various strength.

\begin{tabular}{ll}
\hline Drugs & Strength present in the market \\
\hline 1. Diclofenac suppository & $12.5 \mathrm{mg}, 50 \mathrm{mg}$ \\
2. Ketorolac injection & $10 \mathrm{mg} / \mathrm{ml}, 30 \mathrm{mg} / \mathrm{ml}, 60 \mathrm{mg} / 2 \mathrm{ml}$ \\
3. Ceftriaxone injection & $\begin{array}{l}1 \mathrm{gm} / \mathrm{vial}, 250 \mathrm{mg}, 500 \mathrm{mg}, 2 \\
\mathrm{gm} / \mathrm{vial}\end{array}$ \\
& $20 \mathrm{mg}, 40 \mathrm{mg}$ \\
4. Pantoprazole tablet & $125 \mathrm{mg}, 250 \mathrm{mg}, 500 \mathrm{mg}$ \\
5. Paracetamol suppository & $250 \mathrm{mg} / \mathrm{vial}, 750 \mathrm{mg} / \mathrm{vial}, 1.5$ \\
6. Cefuroxime injection & $\mathrm{gm} / \mathrm{vial}$ \\
7. Amoxicillin injection & $250 \mathrm{mg} / \mathrm{vial}, 500 \mathrm{mg} / \mathrm{vial}$ \\
\hline
\end{tabular}

As shown in the present study, the most common prescription errors out of 978 prescribed medicines were in the name of 35 prescribed drugs, which were not clear due to ambiguous hand writing, strength of medicines were not mentioned in case of 279 drugs whereas these drugs were present in the market in various strengths (Table 4). This study also identified 31 improper abbreviations and 15 prescriptions containing therapeutic duplication. This frequency was low but may cause serious problem because in most of the cases they are known to produce drug- drug interaction. A total of 409 drug interactions were also identified from 200 prescriptions. A previous study in Southeast Ethiopia disclosed the absence of drug information was $23.8 \%$ and improper abbreviation was $2.3 \%$ in southwest Ethiopia (Agalu et al., 2011).

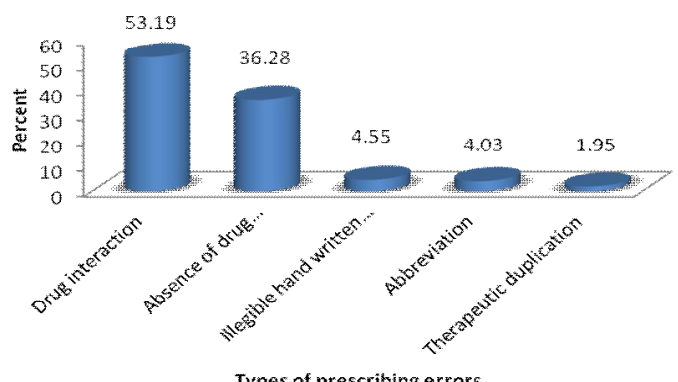

Figure 2. Different types of prescription errors.

Finally, it must be noted that this study did not explore the severity of errors, outcome of treatment or reasons for errors. The use of guidelines rather than clinical opinions to determine error, and the small number of patients included in the study must also be noted. 


\section{Conclusion}

In conclusion, the prescribing practices observed in this study were found to be un-satisfactory, as suggested by polypharmacy and over prescription of antibiotics. The errors reported clearly show that there are multiple causes for prescribing errors. Medication errors at the prescribing phase were highly prevalent for the inpatients in the studied hospital. With the increasing complexity of care in critically ill patients, organizational factors such as the absence of quality assurance measures, error reporting systems, and routine checks could have contributed to the errors reported here. The lack of close supervision for the prescribing medical interns, along with the absence of the clinical pharmacists, could have made things worse. Hospital managers should strive to create better awareness about the possibility of medication errors at the prescribing phase among health care professionals. Introduction of quality assurance measures and routine checks with close supervision of the prescribing intern physicians are strongly recommended. We also recommend the inclusion of the clinical pharmacists in the health care team of the hospital in general.

\section{Acknowledgement}

The authors are thankful to the hospital authority for their co-operation and support to carry out this survey based research.

\section{References}

Agalu, A., Ayele, Y., Bedada, W. and Woldie, M. 2011. Medication prescribing errors in the intensive care unit of Jimma University Specialized Hospital, Southwest Ethiopia. J. Multidisciplin. Healthcare 4, 377-382.

Barber, N.D., and Dean, B.S. 1998. The incidence of medication errors and ways to reduce them. Clin. Risk. 4, 103-106.

Barker, K.N., Flynn, E.A., Pepper, G.A., Bates, D.W. and Mikeal, R.L. 2002. Medication errors observed in 36 healthcare facilities. Arch. Intern. Med. 162, 1897-1903.

Bates, D.W., Cullen, D.J., Laird, N., Petersen, L.A., Small, S.D., Servi, D. 1995. Incidence of adverse drug events and potential adverse drug events, Implication for prevetion. $J$. Am. Med. Assoc. 274, 29-34.
Bimo, H. and Hogerzeil, V. 1999. How to investigate drug use in health facilities- selective drug use indicator. WHO Department of Essential Drug and Medicine policy. p. 3.

Biswas, N.R., Jindal, S., Siddiqui, M. 2001. Patterns of prescription and drug use in ophthalmology in a tertiary hospital in Delhi. Br. J. Clin. Pharmacol. 51, 267-269.

Das, N., Khan, A.N., Badini, Z.A. and Baloch, H. 2001. Prescribing practices of consultants at Karachi, Pakistan. $J$. Pak. Med. Assoc. 51, 74-77.

Dean, B., Barber, N. and Schachter, M. 2000. What is a prescribing error? Qual. Health Care 9, 232-237.

Desai, S. 2001. Essential drugs and rational drug therapy. Bull. Soc. Rational. Ther. 12, 2-7.

Hogerzeil, H.V., Bimo, Ross-Dagnan. D. and Laing, R.O. 1993. Field test for rational drug use in twelve developing countries. Lancet 342, 1408-1410.

Jimoh, A.O., Etuk, E.U., Sani, Z. and Shuaibu, H.A. 2011. The pattern of antibiotic use in a family medicine department of a tertiary hospital in Sokoto, North Western, Nigeria. $J$. Clin. Diagnos. Res. 5, 566-569.

Kumari Indira K.S., S.J., Chandy, L., Suresh, 2008. Antimicrobial prescription patterns for common acute infections in some rural \& urban health facilities of India. Indian. J. Med. Resem. 128, 165-171.

Lamichhane, D.C., Giri, B.R., Pathak, O.K., Panta, O.B. and Shankar, P.R. 2006. Morbidity profile and prescribing patterns among outpatients in a teaching hospital in Western Nepal. McGill. J. Med. 9, 126.

Leape, L.L., Bates, D.W., Cullen, D.J., Cooper, J., Demonaco, H.J. and Gallivan, T. 1995. Systems analysis of adverse drug events. J. Am. Med. Assoc. 274, 35-43.

Moyen, E., Camire, E. and Stelfox, H.T. 2008. Medication errors in critical care. Crit. Care 12, 208.

National Drug Policy. 2005. Ministry of Health and Family Welfare, Government of the People's Republic of Bangladesh. http://www.ddabd.org/download /drug_policy_2005_eng.pdf

Pote, S., Tiwari, P. and Dcruz, S. 2007. Medication prescribing errors in a public teaching hospital in India: a prospective study. Pharmacy Practice 5, 17-20.

Silva, A.M.S. 2009. Inpatients' medical prescription errors. Einstein. 7, 290-294.

Yeasmeen, M., Prabhu, B. and Vidyashree, A. 2011. A drug Utilization Study in the Ophthalmology department of a medical college, Karnataka, India. J. Clin. Diagnos. Res. 5, 82-84. 